\title{
CARACTERIZAÇÃO FÍSICO-QUÍMICA E SENSORIAL DE SUCO ADOÇADO DE AMORA (MORUS NIGRA L.) OBTIDO POR PRENSAGEM E DESPOLPAMENTO
}

\section{PHYSICAL-CHEMICAL AND SENSORIAL CHARACTERIZATION OF MULBERRY (MORUS NIGRA L.) SWEETENED JUICE OBTAINED BY PRESSING AND PULPING}

\author{
Suzana Magda Pimenta ${ }^{1}$, Francy Magdalena Zambrano ${ }^{2}$, Waldemar Gastoni Venturini Filho ${ }^{3}$
}

${ }^{1}$ Serviço Nacional de Aprendizagem Industrial-FATEC-SENAI-MT Brasil.smpimenta@ bol.com.br

${ }^{2}$ Universidade Federal do Triângulo Mineiro-UFTM-Uberaba francyzambrano@ hotmail.com

${ }^{3}$ Universidade Estadual Paulista Júlio de Mesquita Filho-UNESP-Botucatu venturini@ fca.unesp.br

\begin{abstract}
Resumo
Por desconhecimento dos produtores, a amora (Morus nigra L.) apenas tem sido explorada comercialmente para alimentação do bicho-da-seda. No entanto, é uma fruta com possibilidade de aproveitamento tecnológico através da fabricação de diversos produtos com maior valor agregado. O objetivo deste trabalho foi elaborar suco adoçado de amora, através de dois processos de extração utilizando prensa e despolpadora, avaliar as características físicoquímicas e a aceitação sensorial dos sucos obtidos. As matérias-primas utilizadas foram amora (Morus nigra L.), água, benzoato de sódio e açúcar. O teor de sólidos solúveis das bebidas foi de 9,5 11,5 e 13,5 e 9,9 11,9 e 13,9³rix nos sucos obtidos através de prensa hidráulica e despolpadora, respectivamente. Os sucos foram analisados quimicamente quanto a sólidos solúveis, acidez titulável, $\mathrm{pH}$, ratio, açúcares redutores, açúcares redutores totais, sacarose, turbidez e cor. A análise sensorial dos sucos foi feita por meio de teste de aceitação (escala hedônica). A análise estatística (descritiva) dos resultados das análises físico-químicas dos sucos foi feita através do cálculo da média e do desvio padrão, enquanto que para o teste sensorial, foi realizada análise de variância e comparação de médias pelo teste de Tukey $(p<0,05)$. Os sucos obtidos por prensagem e despolpamento não apresentaram diferenças físico-químicas, exceto para turbidez que foi muito maior nos sucos extraídos na despolpadora. No teste sensorial, os provadores preferiram as bebidas mais adoçadas, independentemente do tipo de extração de suco adotado. Os processos de extração (prensagem e despolpamento) não interferiram nas características químicas dos sucos e nem na sua aceitação.
\end{abstract}

Palavras-chave: Bebidas não alcoólica; Morus nigra L.; análise físico-química; análise sensorial.

\section{Introdução}

O foco dos negócios hortifrutícolas brasileiros deve se concentrar no mercado interno, levando em conta a melhor distribuição de renda e o enfraquecimento dos EUA e UE, principais compradores da fruta brasileira (PAGLIUCA, 2012). 
Como consequência do incremento/distribuição na renda do brasileiro existe um maior número de pessoas aptas a consumir frutas e produtos de maior valor agregado (PAGLIUCA, 2012).

O aumento do consumo de suco de frutas está fortemente relacionado a mudanças de hábitos alimentares da população. Dentre esses, pode-se citar a procura intensificada de produtos mais naturais, uma tendência mundial no consumo, para obtenção de uma vida mais saudável (efeitosaúde); a substituição do consumo de outras formas de derivados de frutas, como doces, que são contrários à tendência anterior e a procura de maior conveniência, substituindo o consumo do fruto in natura pelo seu equivalente processado (VILELA, 2013).

Boa parte das frutas que ocorrem no Brasil não é produzida e nem adequadamente aproveitada em escala comercial, mas sim em pomares domésticos. Seu aproveitamento poderia ser melhorado através da sua transformação em geléia, iogurte, sorvete, fermentado, aguardente, licor, bebidas mistas, bebidas lácteas, refresco, néctar, suco, etc., agregando valor econômico a tais produtos que deverão apresentar características sensoriais aceitáveis.

Dentre essas frutas, encontra-se a amora que pode ser do gênero Rubus ou Morus. Poucos são os trabalhos relacionados ao processamento dessas amoras com o objetivo de produzir bebidas, pois a maioria deles se refere ao aproveitamento de componentes químicos da fruta. A amora Rubus é a mais pesquisada com vistas à sua transformação em diversos produtos enquanto que a amora Morus é a mais estudada quanto à sua composição química, principalmente as antocianinas (polifenol).

A legislação brasileira não possui Padrões de Identidade e Qualidade (PIQ) de suco de amora. Define suco ou sumo como a bebida não fermentada, não concentrada e não diluída, destinada ao consumo, obtida da fruta madura e sã, ou de parte do vegetal de origem, através de processamento tecnológico adequado. O produto deve ser submetido a tratamento para sua apresentação e conservação até o momento do consumo; não deve conter substâncias estranhas à fruta ou a partes do vegetal de origem, sendo também proibida a adição de aromas e corantes artificiais. É permitida a adição de açucares (máximo de 10\%) e dióxido de carbono, utilizando-se o termo adoçado e gaseificado, respectivamente (BRASIL, 2009).

A extração do suco da fruta geralmente envolve esmagamento e pressão. O método de extração depende da estrutura da fruta, parte e tipo de tecido onde se encontra o suco e as características desejadas do produto final (CRUESS, 1973).

O suco de amora pode ser extraído através de vários processos, dentre eles o despolpamento e a prensagem. De acordo com Lopes (2005), as despolpadoras podem ser do tipo horizontal, horizontal de rosca e inclinada; enquanto as prensas, do tipo hidráulico, pneumático, esteira contínua e parafuso contínuo. 
Os poucos autores que trabalharam com suco de amora (Morus ou Rubus) não citam em que tipo de equipamento realizaram a extração de suco.

O objetivo deste trabalho foi produzir e caracterizar físico-química e sensorialmente sucos adoçados de amora Morus nigra L. obtidos por prensagem e despolpamento.

\section{Material e métodos}

No processamento do suco adoçado, além de amoras da espécie Morus nigra L., foram utilizados açúcar cristal e benzoato de sódio.

Os tratamentos consistiram em duas formas de extração do suco e três teores de sólidos solúveis na bebida. O suco foi extraído em prensa hidráulica (marca Ribeiro, modelo 15 t) e despolpadora vertical com peneira de malha 0,5mm (marca Mecamau, modelo D-003). Trabalhouse com três concentrações de sólidos solúveis, sendo duas ajustadas a partir dos teores de sólidos solúveis iniciais $\left(9,5^{\circ}\right.$ Brix na prensa e $9,9^{\circ}$ Brix na despolpadora). No total foram realizados seis tratamentos: $\mathrm{T} 1=$ Prensa $/ 9,5{ }^{\circ}$ Brix, $\mathrm{T} 2=$ Prensa $/ 11,5^{\circ}$ Brix , T3 = Prensa $/ 13,5{ }^{\circ}$ Brix, $\mathrm{T} 4=$ Despolpadora $/ 9,9{ }^{\circ}$ Brix, T5 = Despolpadora $/ 11,9{ }^{\circ}$ Brix, T6 = Despolpadora $/ 13,9{ }^{\circ}$ Brix. Os testes foram feitos com duas repetições, somando 12 parcelas experimentais.

A correção do teor de sólidos solúveis dos sucos foi feita por balanço de massa (Equação 2), a partir da definição matemática de ${ }^{\circ}$ Brix (Equação 1).

$$
\begin{gathered}
{ }^{\circ} \text { Brix }=\frac{\text { Massa de sólidos solúveis }}{\text { Massa de solução }} * 100 \\
\mathrm{~B}_{1} * \mathrm{M}_{1}+\mathrm{B}_{2} * \mathrm{M}_{2}=\mathrm{B}_{3} * \mathrm{M}_{3}
\end{gathered}
$$

$\mathrm{B}_{1}=$ teor de sólidos solúveis do suco integral ou original ( ${ }^{\circ}$ Brix $)$

$\mathrm{M}_{1}=$ massa do suco integral ou original $(\mathrm{g})$

$\mathrm{B}_{2}=$ teor de sólidos solúveis do açúcar cristal $\left({ }^{\circ}\right.$ Brix $)$

$\mathrm{M}_{2}=$ massa de açúcar cristal $(\mathrm{g})$

$\mathrm{B}_{3}=$ teor de sólidos solúveis do suco adoçado ( ${ }^{\circ}$ Brix $)$

$\mathrm{M}_{3}=$ massa de suco adoçado $(\mathrm{g})$

As amoras foram colhidas manualmente a cada dois ou três dias. A colheita foi realizada estendendo-se uma lona plástica embaixo das amoreiras e agitando os galhos, para que os frutos caíssem sobre a lona. Após, uma pré-limpeza para retirada de galhos, folhas e insetos, as frutas foram acondicionadas em sacos plásticos com capacidade de $5 \mathrm{~kg}$ e transportadas até o laboratório em veículo não refrigerado. No laboratório, procedeu-se a segunda limpeza das frutas. Durante a 
lavagem em água da rede pública, as amoras também foram separadas, conforme a densidade, em maduras (afundavam) e verdes (flutuavam). A seguir, cada tipo de amora foi acondicionado em sacos plásticos com peso de $2,5 \mathrm{~kg}$ e congelado em freezer doméstico $\left(-18^{\circ} \mathrm{C}\right)$.

O lote de processamento foi composto por várias amostras aleatórias de amoras madura e verde pesadas na proporção de 1:1 (madura:verde) e descongelado em temperatura ambiente $\left(17,5^{\circ} \mathrm{C}\right.$ a $28,4^{\circ} \mathrm{C}$ com média de $\left.23^{\circ} \mathrm{C}\right)$. Na prensa, as amoras foram esmagadas com $6,5 \mathrm{kgf} / \mathrm{cm}^{2} \mathrm{de}$ pressão durante 5 minutos e a separação do bagaço foi feita com o uso de tecido sintético de malha fina do tipo voil. Na despolpadora, o tempo de processamento também foi de 5 minutos. Para ambos os equipamentos, a massa de amora processada em cada batelada foi de $3 \mathrm{~kg}$.

Após a extração do suco integral, o seu teor de sólidos solúveis foi ajustado, conforme previsto nos tratamentos, por adição de açúcar cristal. Foi também adicionado benzoato de sódio para efeito de sua conservação $(0,20 \mathrm{~g} / \mathrm{L})$. Em seguida, os sucos foram acondicionados em garrafas de vidro branco transparente de $500 \mathrm{~mL}$ devidamente esterilizadas em autoclave $\left(121^{\circ} \mathrm{C}\right.$ por 15 min), fechadas com rolhas metálicas rosqueáveis (fervidas no momento do envase) e mantidos sob refrigeração $\left(4-6^{\circ} \mathrm{C}\right)$ por cerca de 15 horas até o momento da analise sensorial.

As análises físico-químicas realizadas foram teor de sólidos solúveis (SS), expresso em ${ }^{\circ}$ Brix, determinado em densímetro digital (marca Mettler, modelo KEM DA-310), acidez titulável (AT), expressa em gramas de ácido cítrico por $100 \mathrm{~mL}$ e pH que foi determinado em pHmetro digital (marca Micronal, modelo B474) e de acordo com BRASIL (2005). O ratio foi calculado pela razão SS/AT. O açúcar redutor (AR) e o açúcar redutor total (ART), expressos em gramas de glicose por $100 \mathrm{~mL}$, foram determinados pelo método titulométrico de Eynon-Lane (COPERSUCAR, 1980). A sacarose, expressa em gramas de sacarose por $100 \mathrm{~mL}$, foi calculada pela diferença de valores entre ART e AR, multiplicando o resultado pelo fator 0,95. Para mensurar a turbidez, expressa em escala NTU, foi utilizado turbidímetro (marca Hach, modelo 2100) com padrões de formazina 20, 200, 1000 e 4000 NTU para a calibração (OIV, 2005). Para a avaliação da cor da bebida, foi realizada varredura de absorbância (A) nos comprimentos de onda do espectro visível (400 a 800nm), utilizando espectrofotômetro (marca GBC, modelo Cintra 40 UV-Visível). Para isso as amostras foram previamente centrifugadas, filtradas em filtro de papel e diluídas 100x. Todas as análises físico-químicas foram realizadas em triplicata.

$\mathrm{Na}$ análise sensorial, foi realizado teste de aceitação por escala hedônica (DUTCOSKY, 2011) e calculados os índices de aprovação, rejeição e indiferença. Foram comparadas entre si as amostras dos tratamentos T1, T2 e T3, e as amostras dos tratamentos T4, T5 e T6. Os testes foram realizados com painel de 100 provadores não selecionados e não treinados, de ambos os sexos, na faixa etária de 20 a 50 anos (CHAVES; SPROESSER, 1999; MORAES, 1993). Os atributos avaliados foram aparência, odor, sabor e avaliação geral, utilizando escala hedônica estruturada de 
nove pontos $(9=$ gostei muitíssimo; $8=$ gostei muito; $7=$ gostei regularmente; $6=$ gostei ligeiramente; 5 = não gostei nem desgostei; 4 = desgostei ligeiramente; 3 = desgostei regularmente; 2 = desgostei muito; 1 = desgostei muitíssimo). Foram servidas para cada provador três amostras com $50 \mathrm{~mL}$ de bebida, em taças de vidro transparente. Junto com as amostras, também foi servido um copo de água. Todas as amostras foram casualizadas e codificadas com três dígitos. Os testes sensoriais foram aprovados pelo Comitê de Ética em Pesquisa (CEP) da Universidade onde esses foram realizados.

A análise estatística (descritiva) dos resultados das análises físico-químicas dos sucos foi feita através do cálculo da média e do desvio padrão. Nos testes sensoriais, foi realizada a análise de variância (ANOVA) e a comparação de médias foi feita pelo teste de Tukey a 5\% de probabilidade (SAEG, 1993).

\section{Resultados e discussão}

Na Tabela 1, são apresentados os resultados da caracterização físico-química dos sucos integrais e adoçados de amora obtidos por prensagem e despolpamento. Os resultados da caracterização química dos sucos integrais obtidos por prensagem e despolpamento são semelhantes aos publicados por Pimenta et al., (2012) que trabalharam de forma semelhante, com o mesmo tipo de matéria-prima: SS 10,8 Brix; AT 0,74\%; Ratio 14,5; pH 4,01; AR 8,38\%; ART 8,61\% e turbidez 221 NTU, para suco integral obtido em prensa, e SS 11,2 Brix; AT 0,80\%; Ratio 13,9; pH 3,93; AR 8,80\%; ART 9,11\% e turbidez acima de 4.000 NTU, para suco integral extraído em despolpadora.

Os resultados apresentados na Tabela 1 mostram que os sucos obtidos por prensagem e despolpamento apresentaram características similares, exceto com relação à turbidez que foi maior nos sucos extraídos na despolpadora. Este equipamento causa a fragmentação dos tecidos vegetais, originando material particulado (sólidos insolúveis), de tamanho coloidal ou acima dele, que turvam a bebida. Já, na extração com prensa, a quantidade de células fragmentadas é menor, resultando em bebidas menos turvas.

Os dados dessa tabela mostram ainda que o ratio das bebidas elevou-se com o teor de sólidos solúveis e que a acidez e o pH não sofreram alteração. Como os resultados de AR e ART são próximos para cada tipo de suco, pode-se tirar duas conclusões: a) nos sucos integrais, fica evidente que a amora Morus usada no teste não acumula sacarose, indicando que as concentrações de AR observadas deve-se à presença de frutose e/ou glicose no suco da fruta; b) nos sucos 
adoçados, toda sacarose usada para elevar seus Brix foi hidrolisada, cujo processo foi facilitado pelo baixo pH dessas bebidas, conforme previsto por Belitz et al., (2009).

Tabela 1 - Caracterização físico-química de sucos integrais e adoçados de amora obtidos por prensagem e despolpamento

\begin{tabular}{|c|c|c|c|c|c|c|}
\hline \multirow{2}{*}{ Análise } & \multicolumn{3}{|c|}{ Prensa } & \multicolumn{3}{|c|}{ Despolpadora } \\
\hline & 9,5 $5^{\circ}$ rix & $11,5^{\circ}$ Brix & $13,5^{\circ}$ Brix & $9,9^{\circ}$ Brix & $11,9^{\circ}$ Brix & $13,9^{\circ}$ Brix \\
\hline $\begin{array}{c}\text { SS } \\
\left({ }^{\circ} \text { Brix }\right)\end{array}$ & $\begin{array}{c}9,53 \\
\pm 0,33\end{array}$ & $\begin{array}{r}11,53 \\
\pm 0,33\end{array}$ & $\begin{array}{r}13,53 \\
\pm 0,33\end{array}$ & $\begin{array}{c}9,90 \\
\pm 0,00\end{array}$ & $\begin{array}{l}11,90 \\
\pm 0,00\end{array}$ & $\begin{array}{r}13,90 \\
\pm 0,00\end{array}$ \\
\hline $\begin{array}{c}\mathrm{AT} \\
\left(\mathrm{g} 100 \mathrm{~mL}^{-1}\right)\end{array}$ & $\begin{array}{c}0,72 \\
\pm 0,01\end{array}$ & $\begin{array}{c}0,69 \\
\pm 0,02\end{array}$ & $\begin{array}{c}0,71 \\
\pm 0,00\end{array}$ & $\begin{array}{c}0,68 \\
\pm 0,01\end{array}$ & $\begin{array}{c}0,67 \\
\pm 0,02\end{array}$ & $\begin{array}{c}0,68 \\
\pm 0,01\end{array}$ \\
\hline Ratio & $\begin{array}{r}13,24 \\
\pm 0,62\end{array}$ & $\begin{array}{l}16,50 \\
\pm 0,84\end{array}$ & $\begin{array}{c}18,87 \\
\pm 0,34\end{array}$ & $\begin{array}{l}14,45 \\
\pm 0,29\end{array}$ & $\begin{array}{l}17,58 \\
\pm 0,41\end{array}$ & $\begin{array}{r}20,15 \\
\pm 0,33\end{array}$ \\
\hline $\mathrm{pH}$ & $\begin{array}{c}4,05 \\
\pm 0,02\end{array}$ & $\begin{array}{c}4,04 \\
\pm 0,01\end{array}$ & $\begin{array}{c}3,99 \\
\pm 0,05\end{array}$ & $\begin{array}{c}3,95 \\
\pm 0,03\end{array}$ & $\begin{array}{c}3,93 \\
\pm 0,02\end{array}$ & $\begin{array}{c}3,92 \\
\pm 0,04\end{array}$ \\
\hline $\begin{array}{c}\text { ART } \\
\left(\mathrm{g} 100 \mathrm{~mL}^{-1}\right)\end{array}$ & $\begin{array}{c}9,65 \\
\pm 0,14\end{array}$ & $\begin{array}{l}10,97 \\
\pm 0,0\end{array}$ & $\begin{array}{c}12,41 \\
\pm 0,04\end{array}$ & $\begin{array}{c}9,96 \\
\pm 0,02\end{array}$ & $\begin{array}{r}10,75 \\
\pm 0,01\end{array}$ & $\begin{array}{r}11,06 \\
\pm 0,05\end{array}$ \\
\hline $\begin{array}{c}\mathrm{AR} \\
\left(\mathrm{g} 100 \mathrm{~mL}^{-1}\right)\end{array}$ & $\begin{array}{c}9,57 \\
\pm 0,15\end{array}$ & $\begin{array}{c}10,80 \\
\pm 0,20\end{array}$ & $\begin{array}{l}11,65 \\
\pm 0,06\end{array}$ & $\begin{array}{c}8,99 \\
\pm 0,03\end{array}$ & $\begin{array}{l}10,26 \\
\pm 0,01\end{array}$ & $\begin{array}{r}10,99 \\
\pm 0,01\end{array}$ \\
\hline $\begin{array}{l}\text { Sacarose } \\
\left(\mathrm{g} 100 \mathrm{~mL}^{-1}\right)\end{array}$ & $\begin{array}{c}0,07 \\
\pm 0,01\end{array}$ & $\begin{array}{c}0,15 \\
\pm 0,22\end{array}$ & $\begin{array}{c}0,72 \\
\pm 0,02\end{array}$ & $\begin{array}{c}0,92 \\
\pm 0,01\end{array}$ & $\begin{array}{c}0,46 \\
\pm 0,01\end{array}$ & $\begin{array}{c}0,06 \\
\pm 0,04\end{array}$ \\
\hline $\begin{array}{c}\text { Turbidez } \\
\text { (NTU) }\end{array}$ & $\begin{array}{l}456,50 \\
\pm 0,71\end{array}$ & $\begin{array}{l}458,50 \\
\pm 0,71\end{array}$ & $\begin{array}{l}456,50 \\
\pm 0,71\end{array}$ & $\begin{array}{l}>4000 \\
\pm 0,00\end{array}$ & $\begin{array}{l}>4000 \\
\pm 0,00\end{array}$ & $\begin{array}{l}>4000 \\
\pm 0,00\end{array}$ \\
\hline
\end{tabular}

A Figura 1 mostra que todos os sucos de amora absorveram luz na faixa dos $520 \mathrm{~nm}$.

Figura 1 - Absorção de luz visível pelos sucos obtidos por prensa e despolpadora

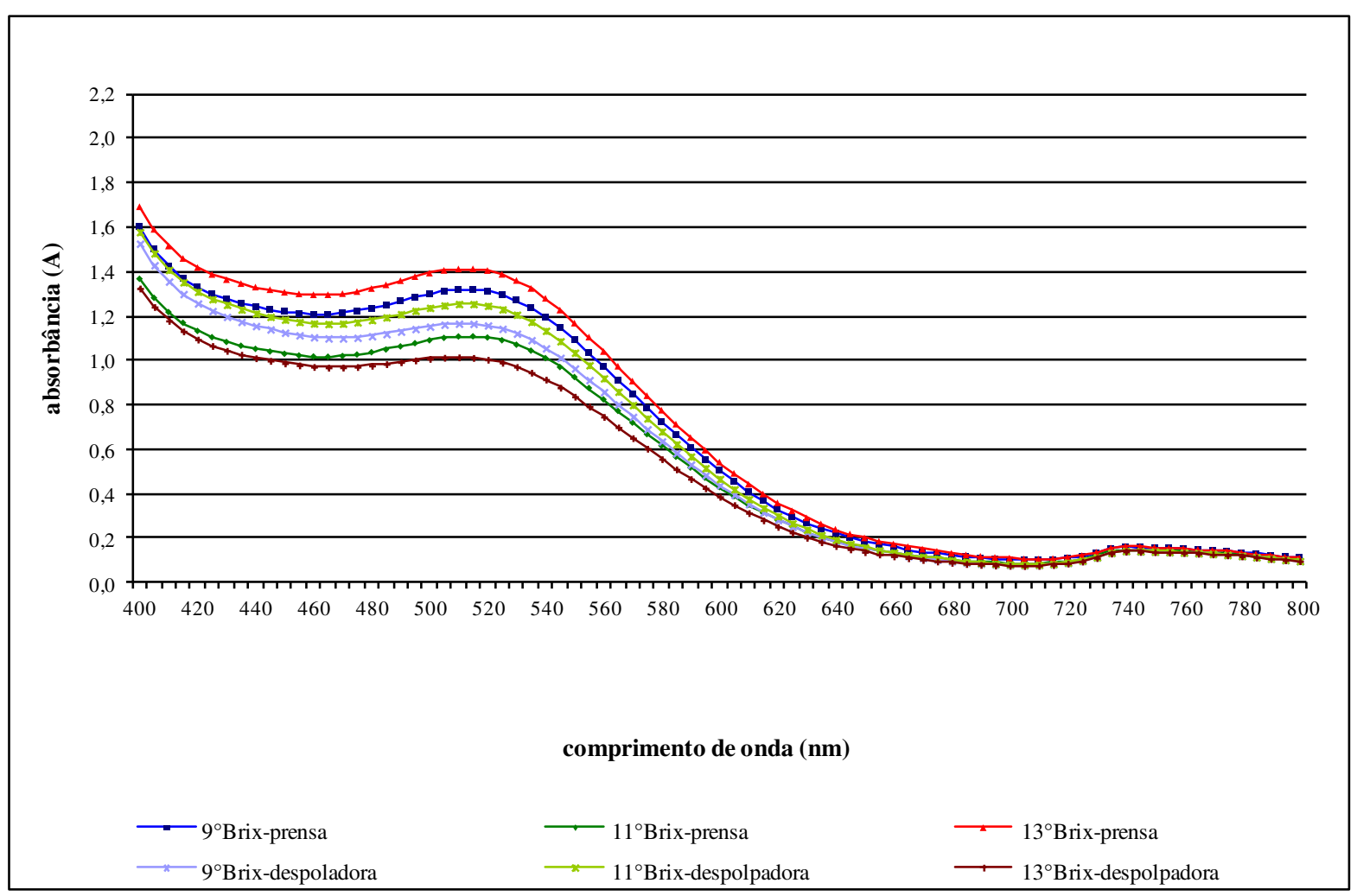


De acordo com Timberlake (1980), entre as antocianinas conhecidas, é a pelargonidina que apresenta pico de absorção neste comprimento de onda. Ribeiro e Seravalli (2004) afirmam que a pelargonidina é encontrada em morango e amora, o que confirma os resultados obtidos no presente trabalho.

O teste sensorial de aceitação é utilizado quando se deseja conhecer o comportamento afetivo do consumidor com relação a um determinado produto (BRASIL, 2005). Na presente pesquisa, as notas do atributo sabor melhoraram de forma significativa ( $p>0,05)$ com o aumento do teor de sólidos solúveis nas bebidas, tanto para as obtidas com suco extraído da prensa como para aquelas provenientes da extração em despolpadora (Tabela 2). Estes resultados mostram que os provadores preferiram as bebidas mais adocicadas. As notas da avaliação geral das bebidas acompanharam as notas do sabor. Estas variaram de 5,25 a 7,32 e situaram-se entre "indiferente" e "gostei muito".

Tabela 2 - Teste de aceitação dos sucos adoçados de amora extraídos em prensa e despolpadora

\begin{tabular}{ccccccc}
\hline \multirow{2}{*}{ Atributos } & \multicolumn{7}{c}{ Tratamento } \\
\cline { 2 - 7 } & T1 & T2 & T3 & T4 & T5 & T6 \\
\hline Aparência & $7,21 \mathrm{a}$ & $7,24 \mathrm{a}$ & $7,14 \mathrm{a}$ & $6,54 \mathrm{a}$ & $6,50 \mathrm{a}$ & $6,76 \mathrm{a}$ \\
Odor & $5,73 \mathrm{a}$ & $5,74 \mathrm{a}$ & $5,77 \mathrm{a}$ & $5,72 \mathrm{a}$ & $5,94 \mathrm{a}$ & $5,86 \mathrm{a}$ \\
Sabor & $5,25 \mathrm{c}$ & $6,18 \mathrm{~b}$ & $7,32 \mathrm{a}$ & $5,04 \mathrm{c}$ & $6,14 \mathrm{~b}$ & $7,06 \mathrm{a}$ \\
Avaliação Geral & $5,79 \mathrm{~b}$ & $6,21 \mathrm{~b}$ & $7,18 \mathrm{a}$ & $5,75 \mathrm{c}$ & $6,40 \mathrm{~b}$ & $7,18 \mathrm{a}$ \\
\hline Médias com a mesma letra minúscula na linha comparam níveis de doçura dentro de cada equipamento pelo teste de Tukey a 5\% de probabilidade.
\end{tabular}

Segundo Rousmans et al., (2000) a maior aceitação pelo sabor doce com implicações na análise sensorial de alimentos e bebidas pode ser explicado pela inata aceitação química por esse sabor. Esses autores citam que a evolução, adaptação e seleção natural das espécies resultaram na produção de sistemas fisiológicos que produzem a sensação de prazer em resposta a estímulos gustativos devido à presença de nutrientes necessários (por exemplo da sacarose) ou de moléculas que carregam energia e de desgosto em resposta a estímulos relacionados com a presença de toxinas geralmente de sabor amargo.

As notas do atributo aparência variaram entre os valores de 6,5 (suco obtido na despolpadora) e 7,2 (suco obtido na prensa), indicando boa aceitabilidade por parte dos provadores. Já o atributo odor, para todos os sucos, recebeu notas um pouco acima da indiferença (5). Este resultado é perfeitamente compreensível, uma vez que a amora (Morus nigra L.) não possui aroma característico de fruta; na verdade, não possui aroma algum.

A Figura 2 mostra que para os sucos mais adocicados (13,5 e 13,9 ${ }^{\circ}$ Brix $)$, extraídos tanto na prensa como na despolpadora, a nota mais freqüente dos atributos sabor e avaliação geral foi 8 (gostei muito). Para os sucos com 11,5 e 11,9 ${ }^{\circ}$ Brix, a nota mais freqüente foi 7 (gostei 
regularmente) e para os sucos com 9,5 e $9,9^{\circ}$ Brix, as notas que prevaleceram ficaram entre 6 e 7 (gostei ligeiramente e gostei regularmente).

Figura 2 - Distribuição de freqüência das notas hedônicas dos atributos sabor e avaliação geral dos sucos de amora extraídos em prensa e despolpadora
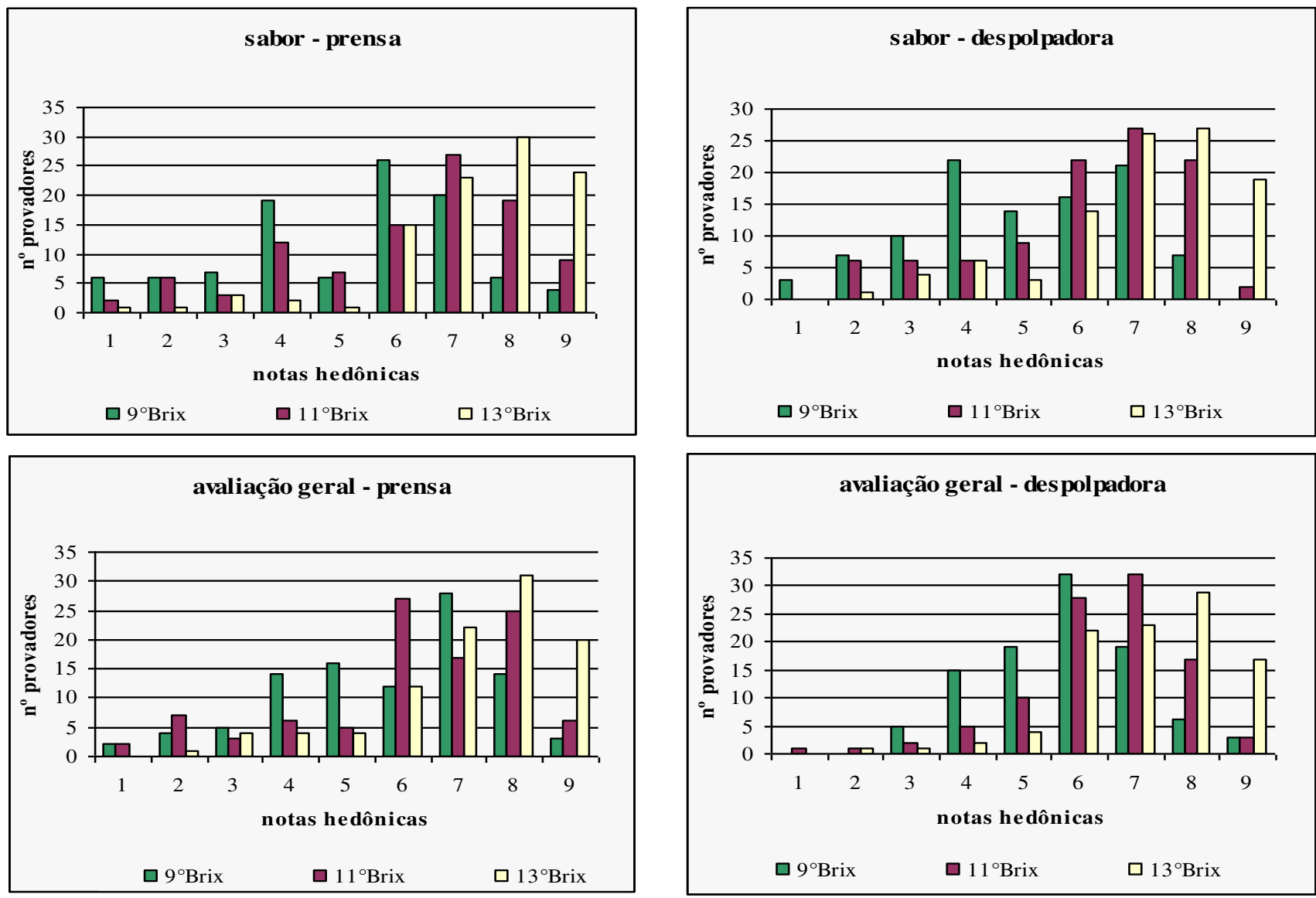

A porcentagem de aprovação (notas acima de 6) para os atributos sabor e avaliação geral foi crescente com o aumento do teor de sólidos solúveis nas bebidas (Figura 3, p. 1126). O percentual de aprovação desses atributos nos sucos mais adocicados ficou acima de $86 \%$, atingindo um máximo de $92 \%$.

\section{Conclusões}

Os equipamentos (prensa e despolpadora) testados na extração não interferiram nas características físico-químicas dos sucos adoçados de amora, exceto na sua turbidez.

A análise sensorial revelou que os sucos com maior teor de sólidos solúveis (mais doces) foram mais bem aceitos em termos de sabor e avaliação geral pela equipe de provadores, sem influência do tipo de equipamento utilizado na fabricação da bebida.

O teor de sólidos solúveis (doçura) e o tipo de equipamento de extração não interferiram na aparência e no odor dos sucos. 
Entre os atributos sensoriais avaliados, o odor ficou com as menores notas em função da pobreza de compostos aromáticas presentes na amora (Morus nigra L.).

Figura 3 - Porcentagem de aprovação, indiferença e rejeição dos sucos de amora extraídos em prensa e despolpadora
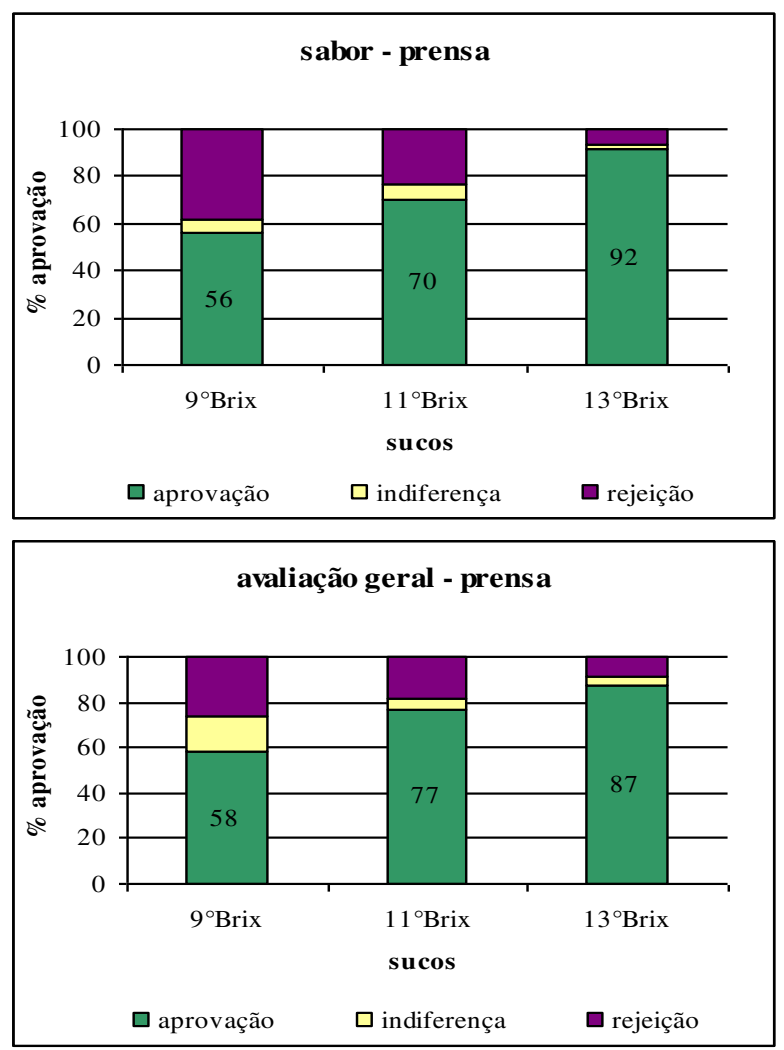
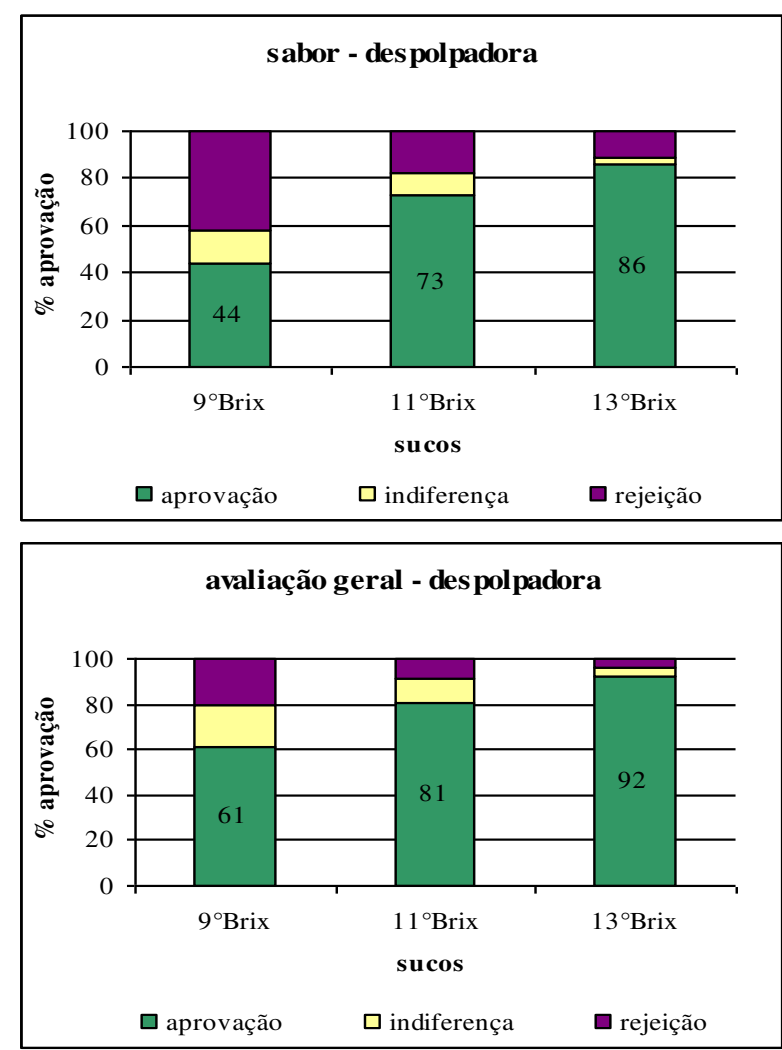

\begin{abstract}
Lacking knowledge, mulberry (Morus nigra L.) producers has been only commercially exploiting berries as silkworm food. Although, the fruit holds great technological uses to produce higher value-added goods. The objective was to elaborate sweeten mulberry juice by two extraction processes with press and depulper, and yet to evaluate physicalchemical characteristics and the sensory acceptance of the juices. Materials used were mulberry berries (Morus nigra L.), water, sodium benzoate and sugar. Soluble solids content were 9,5 11,5 13,5 and 9,9 11,9 13,9 ${ }^{\circ}$ Brix for juices from hydraulic press and depulper, respectively. Juices were chemically accessed for soluble solids, titrable acidity, pH, ratio, reducing sugars, total reducing sugars, sucrose, turbidity and color. Sensory analysis was acceptance testing (hedonic scale). Statistics (descriptive) for the results were carried through means and standard deviation, moreover, for sensory analysis statistics were variance analysis, and means through Tukey $(p<0,05)$. Juices from pressing and depulper showed no physical-chemical differences, but for turbidity that was greater for depulper juices. During sensory testing, panelists preferred sweeten beverages for both extractions. Extraction processes (pressing and depulper) had no interference on chemical characteristics and acceptance.
\end{abstract}

Key-words: non-alcoholic beverages, Morus nigra L, physical-chemical analysis, sensorial analysis.

\title{
Referências
}

BELITZ, H. D.; GROSCH, W.; SCHIEBERLE, P. Carbohydrates. In: . Food Chemistry. Berlin: Springer, 2009. cap. 4 , p. $248-339$.

BRASIL. Ministério da Agricultura, Pecuária e Abastecimento. Decreto no 6871, de 04/06/2009, publicada no DOU de 05/06/2009. Regulamenta a Lei no 8.918, de 14/071994, que dispõe sobre a padronização, a classificação, o registro, a 
inspeção, a produção e a fiscalização de bebidas, 2009. Disponível em <http://www.planalto.gov.br/ccivil_03/Ato20072010/2009/Decreto/D6871.htm.> Acesso em: 30 de junho de 2011.

BRASIL. Ministério da Saúde. Agência Nacional de Vigilância Sanitária. Métodos físico-químicos para análise de alimentos. Brasília: Ministério da Saúde, 2005. 1018p.

CHAVES, J.B.P.; SPROESSER, R.L. Práticas de laboratório de análise sensorial de alimentos e bebidas. Viçosa: Universidade Federal de Viçosa, 1999. 81p. (Cadernos Didáticos, 66).

COPERSUCAR - COOPERATIVA CENTRAL DOS PRODUTORES DE AÇÚCAR E ÁLCOOL DO ESTADO DE SÃO PAULO. Amostragem e análise da cana-de-açúcar. Piracicaba: COPERSUCAR, 1980. 37p.

CRUESS, W. V. Produtos industriais de frutas e hortaliças. São Paulo: Edgard Blücher, 1973. 446p.

DUTCOSKY, S.D. Análise sensorial de alimentos. 3 ed. Curitiba: Champagnat, 2011. 423p.

LOPES, A. S. Pitanga e acerola: estudo de processamento, estabilidade e formulação de néctar misto. 2005. Tese (Doutorado em Tecnologia de Alimentos) - Universidade Estadual de Campinas, Faculdade de engenharia de alimentos, Departamento de Tecnologia de Alimentos.

MORAES, M. A. C. Métodos para avaliação sensorial dos alimentos. 8. ed. Campinas: UNICAMP, 1993. 93p.

OIV - ORGANISATION INTERNATIONALE DE LA VIGNE ET DU VIN. Recueil dês methods internationales d'analyse dês vins et dês mounts. Turbidité des vins. MA-F-AS2-08-TURBID. v. 1. $5^{\mathrm{a}}$ ed. 2005. Disponível em: <http://news.reseau-concpt.net/images/oiv/Client/ RECUEIL\% 202005.pdf>. Acesso em: mar 2010.

PAGLIUCA, L. G. Projeto hortifruti Brasil. Características e principais atividades. Universidade de São Paulo. Escola $\begin{array}{llllll}\text { Superior de } & \text { Agricultura } & \text { Luiz }\end{array}$ <http://www.lpv.esalq.usp.br/lpv661/Fruticultura\%20\%20Economia\%20e\%20Mercados.pdf>. Acesso em: 26 de janeiro 2013.

PIMENTA, S. M.; ZAMBRANO, F.; VENTURINI FILHO, W. G. Suco integral de amora (Morus nigra L.) obtido através de prensagem e despolpamento: rendimento e caracterização físico-química. Alimentos e Nutrição, Araraquara, v. 23, n. 2, p. 335-339, abr./jun. 2012.

RIBEIRO, E P.; SERAVALLI, E. A. G. Química de alimentos. São Paulo: Edgard Blücher, 2004. 184p.

ROUSMANS, S.; ROBIN, O.; DITTMAR, A.; VERNET-MAURY, E. Autonomic nervous system responses associated with primary tastes. Chemical Sense, Oxford, v. 25, p. 709-718, 2000. http://dx.doi.org/10.1093/chemse/25.6.709

SAEG - Sistema para análises estatísticas e genéticas. Versão 5.0. Viçosa, MG: Fundação Arthur Bernardes, 1993.

TIMBERLAKE, C.F. Anthocyanins-occurrence, extraction and chemistry. Food Chemistry, Oxford, v. 5, p. 69-80, 1980. http://dx.doi.org/10.1016/0308-8146(80)90065-5

VILELA, P.S. Federação de Agricultura do Estado de Minas Gerais. Análise da oferta e demanda de frutas no Brasil para o decênio2001/2010. 2013.

$<$ http://www.faemg.org.br/Content.aspx ?Code=348\&ParentPath=None; 13\&ContentVersion=C\&ParentCode=>. Acesso em : 26 de janeiro de 2013.

Submetido em 05 fev. 2013, Aceito para publicação em 16 jul. 2013. 